\title{
(In)visibilidades sociocomunicacionais na diáspora queer ${ }^{\star}$
}

\section{Theodoro Hadriel ${ }^{1}$ Denise Cogo}

Recibido: 04/04/2019

Aprobado por pares: 17/06/2019
Enviado a pares: 22/04/2019

Aceptado: 04/07/2019

DOI: $10.5294 /$ pacla.2020.23.3.2

\section{Para citar este artículo / to reference this article / para citar este artigo}

Theodoro, H. G. S. y Cogo, D. (2020). (In)visibilidades sociocomunicacionais na diáspora queer. Palabra Clave, 23(3), e2332. https://doi.org/10.5294/pacla.2020.23.3.2

\section{Resumo}

O objetivo deste artigo é refletir acerca das dinâmicas de (in)visibilidade inscritas nas experiências de sujeitos LGBTIQ+ (lésbicas, gays, bissexuais, travestis, transgêneros, transexuais, intersexo, queer e outras minorias de gênero e/ou sexuais) migrantes e como podem influir em suas interações sociocomunicacionais e no exercício de cidadania. Assim, elabora-se uma revisão de literatura com o intuito de contextualizar as particularidades do que se pode nomear de "diáspora queer" e sua interface com o binômio comunicação-cidadania. Em articulação com as reflexões teóricas desenvolvidas, propõem-se a sistematização e a análise de dados parciais de uma incursão empírica relacionada à imigração LGBTIQ+ na cidade de São Paulo, Brasil. A partir dessas duas vertentes (teórica e analítica), verifica-se a constituição de espaços e de dinâmicas de (in)visibilidade institucionais e não institucionais - acerca da migração de sujeitos LGBTIQ+, o que possibilita pensar sobre sua existência e sobre as articulações para a garantia de direitos e para uma maior participação cidadã.

\footnotetext{
* As reflexões e análises apresentadas neste artigo estão vinculadas ao desenvolvimento de uma pesquisa de doutorado realizada no Programa de Pós-Graduação em Comunicação e Práticas de Consumo da Escola Superior de Propaganda e Marketing de São Paulo (PPGCOM-ESPM), desde fevereiro de 2017, sob a orientação da Prof. ${ }^{a}$ Dr.a Denise Cogo. O estudo é financiado pela Fundação de Amparo à Pesquisa do Estado de São Paulo (processo n. 2016/24566-1).

$1 \bowtie$ https://orcid.org/0000-0001-8491-4544. Escola Superior de Propaganda e Marketing, Brasil.41710003@acad.espm.br

2 https://orcid.org/0000-0003-4544-7335. Escola Superior de Propaganda e Marketing, Brasil. denise.cogo@espm.br
} 


\section{Palavras-chave (Fonte: tesauro da Unesco)}

Diáspora; diáspora queer; migração; migração LGBTIQ+; comunicação; cidadania.

\section{(In)visibilidades sociocomunicacionales en la diáspora queer ${ }^{\star}$}

\section{Resumen}

El objetivo del artículo es reflexionar acerca de las dinámicas de (in)visibilidad inscritas en las experiencias de sujetos LGBTIQ+ (lesbianas, gays, bisexuales, travestis, transgéneros, transexuales, intersexuales, queer y otras minorías de género y/o sexuales) migrantes y cómo pueden influir en sus interacciones sociocomunicacionales y en el ejercicio de ciudadanía. Así, se elabora una revisión de literatura con el fin de contextualizar las particularidades de lo que se puede nombrar de "diáspora queer" y su interfaz con el binomio comunicación-ciudadanía. En articulación con las reflexiones teóricas desarrolladas, se proponen la sistematización y análisis de datos parciales de una incursión empírica relacionada con la inmigración LGBTIQ+ en la ciudad de São Paulo, Brasil. Desde esas dos vertientes (teórica y analítica), se encuentra la constitución de espacios y dinámicas de (in)visibilidad - institucionales y no institucionales — acerca de la migración de sujetos LGBTIQ+, lo que posibilita pensar sobre su existencia y las articulaciones a la garantía de derechos y a una mayor participación ciudadana.

\section{Palabras clave (Fuente: tesauro de la Unesco)}

Diáspora queer; diáspora; migración LGBTIQ+; migración; comunicación; ciudadanía.

Las reflexiones y análisis presentadas en este artículos están vinculadas en el desarrollo de una investigación de doctorado realizada en el programa de posgrados en comunicación y prácticas de consumo de la Escola Superior de Propaganda e Marketing de São Paulo (PPGCOM-ESPM), desde febrero de 2017, con la orientación de la profesora Dra. Denise Cogo. El estudio fue financiado por la Fundação de Amparo à Pesquisa do Estado de São Paulo (proceso número: $2016 / 24566-1)$. 


\section{Sociocommunicational (in)visibilities in the/of the queer diaspora*}

\section{Abstract}

The aim of this article is to reflect on the (in)visibility dynamics registered in the experiences of LGBTIQ+ (lesbian, gay, bisexual, transvestite, transgender, transsexual, intersex, queer and other gender and/or sexual minorities) migrant subjects and how they can influence their socio-communicative interactions and the exercise of citizenship. Thus, a literature review is developed with the purpose of contextualizing the particularities of what can be called the queer diaspora and its interface with the binomial communication-citizenship. In articulation with the theoretical reflections developed, it is proposed to systematize and analyze partial data of an empirical incursion related to LGBTIQ+ immigration in the city of São Paulo. From these two aspects (theoretical and analytical), it is verified the constitution of spaces and dynamics of (in)visibility - institutional and non-institutional - about the migration of LGBTIQ+ subjects, making possible to think about their existence and the articulations with the guarantee of rights and greater citizen participation.

\section{Keywords (Source: Unesco Thesaurus)}

Queer diaspora; diaspora; LGBTIQ+ migration; migration; communication; citizenship.

* The reflections and analysis in this paper belong to the doctorate research made in the postgraduate program in Communication and consumption practices of the Escola Superior de Propaganda e Marketing de São Paulo (PPGCOM-ESPM), since February 2017. It has the orientation of Dr. Denise Cogo. The study was financed by the Fundação Amparo à Pesquisa do Estado de São Paulo (number: 2016/24566-1). 


\section{Introdução}

Até a década de 1980, a reflexão acadêmica em ciências humanas acerca dos deslocamentos humanos esteve orientada predominantemente por valores tradicionais e patriarcais (Alencar-Rodrigues, Strey e Espinosa, 2009).Em decorrência disso, as migrações foram apreendidas principalmente sob uma perspectiva masculina, que ocultava a presença das mulheres nesse processo. Segundo Assis (2007), mesmo sempre tendo sido parte integrante dos fluxos migratórios, as mulheres não eram percebidas como sujeitos, e a "migrante" se condicionava a um sentido quase fixo de "homem". A personificação do "homem migrante" revela um viés de representação a respeito de quem migra que nos demanda o esforço de produzir uma "correção do olhar" (Krzeslo, 2007).

Desde a maior inserção de um viés feminista nos estudos migratórios (igualmente a partir da década de 1980), observam-se esforços para se questionar e problematizar o que pode ser considerado uma subordinação do feminino, facultando "o reconhecimento e a análise da especificidade das trajetórias, da distribuição das responsabilidades e das tarefas, e concomitantemente da dinâmica das diferenciações das estratégias entre mulheres e homens em relação às sociedades de acolhida" (Krzeslo, 2007, p. 124 , tradução nossa). Ter em mente as reflexões concernentes às questões de gênero nos fluxos migratórios contribui para compreender as camadas múltiplas de silenciamentos e invisibilidades que recaem sobre as experiências de migrantes LGBTIQ+ (lésbicas, gays, bissexuais, travestis, transgêneros, transexuais, intersexo, queer e outras minorias de gênero e/ou sexuais) ou do que podemos intitular de "diáspora queer".

O conceito de "diáspora” está relacionado a uma dupla diferenciação: por um lado, impõe um processo de exclusão e, por outro, estabelece a construção de um "Outro" que delimita posicionamentos circunscritos entre o dentro e o fora, entre o que pertence e o que não faz parte (Hall, 2013). Já "queer" se associa, de forma intrínseca, ao conceito de "abjeção", que se refere às vidas que não são lidas como "vivenciáveis", e cuja materialidade não é tomada como legítima (Butler, 2011). Essa condição menos-que-humana se enraíza nas experiências de sujeitos LGBTIQ+, marcadas por diferentes tipos de preconceito, discriminação e vulnerabilidade. 
A diáspora queer, nesse sentido, corresponde a um processo histórico (Wesling, 2008). Junto a outros marcadores sociais de diferença, tais como origem étnica, raça e classe, o gênero e a orientação sexual emergem como importantes variáveis a serem consideradas nos estudos migratórios. Isso porque elas afetam o deslocamento e a (re)inserção no contexto sociocultural em que o sujeito migrante se encontra. Aí se encontra a importância de nos voltarmos às dinâmicas de (in)visibilidade sociocomunicacionais engendradas nos fluxos migratórios, pois elas nos permitem verificar como sua diversidade é transposta às representações das vivências de quem migra. Já não cabe tomar os fluxos migratórios como um grupo de pessoas hegemonicamente masculinas, heterossexuais e cisgêneras ${ }^{3}$.

Dada essa conjuntura, objetivamos, neste artigo, problematizar de que forma tais dinâmicas de (in)visibilidade se inscrevem nas experiências de sujeitos LGBTIQ+ migrantes e como podem impactar em suas interações sociocomunicacionais e no exercício de cidadania. Para tanto, partimos de uma revisão de literatura, a fim de contextualizar melhor as particularidades da diáspora queer e sua interface com o binômio comunicação-cidadania. Em seguida, propomos a sistematização de dados de uma incursão empírica, de caráter exploratório, que compõe o trabalho de campo da referida pesquisa, a partir dos três eixos centrais descritos a seguir.

1. Entrevistas com imigrantes $L G B T I Q+$ : refere-se a duas entrevistas semiestruturadas, realizadas com Ana, uma mulher lésbica estadunidense, e com Maria, uma mulher transgênera finlandesa. Elas ocorreram nos meses de setembro e outubro de 2016, respectivamente. Seu roteiro esteve orientado às dimensões do projeto migratório (os motivos da vinda ao Brasil, a chegada ao país, a adaptação/integração e os usos e apropriações de mídias nesse processo) e às experiências migratórias vividas no Brasil e na cidade de São Paulo (dificuldades enfrentadas, semelhanças e diferenças com o país de origem, interação com os espaços da cidade $)^{4}$. O intuito foi, além de verificar a viabilidade

3 Cisgeneridade diz respeito à identificação com os códigos socioculturais correspondentes ao gênero designado ao sujeito ao nascer.

4 As entrevistas tiveram duração média de 40 minutos cada; foram gravadas e, posteriormente, transcritas. O nome das entrevistadas foi alterado para preservar seu anonimato (cf. Theodoro e Cogo, 2019). 
da pesquisa, compor um panorama preliminar de vivências de imigrantes LGBTIQ+ residentes na cidade de São Paulo.

2. Observação de institucionalidades: diz respeito a uma abordagem centrada na observação e na coleta de materiais em espaços institucionais que envolvem imigrantes LGBTIQ+ na cidade de São Paulo. Ela se pauta: a) na "Roda de conversa: imigrantes e refugiados/as LGBT em São Paulo: desafios da acolhida e da integração local”, ocorrida em setembro de 2016. O evento foi promovido pelo Centro de Referência e Atendimento para Imigrantes (CRAI), serviço da Secretaria Municipal de Direitos Humanos e Cidadania (SMDHC) da Prefeitura de São Paulo, em parceria com o Serviço Franciscano de Solidariedade (Sefras); b) em uma entrevista semiestruturada efetuada em setembro de 2017 com membros da SMDHC: Camila Barrero, assessora da coordenação de imigrantes, e Ricardo Olimpio Bezerra, coordenador técnico na coordenação de políticas para LGBT. O propósito foi apurar o desenvolvimento e a prática de políticas públicas destinadas a imigrantes LGBTIQ+ na cidade de São Paulo; c) na Cartilha informativa sobre a proteção de pessoas refugiadas e solicitantes de refúgio LGBTI ${ }^{5}$, desenvolvida pelo Alto Comissariado das Nações Unidas para os Refugiados (ACNUR-ONU). A iniciativa é resultado de uma parceria entre a Campanha Livres \& Iguais (projeto da Organização das Nações Unidas - ONU) e a Fundação Purpose.

3. Observação de espaços de agenciamento de coletivos migrantes: concerne à participação no Sarau Troca \& Ação, promovido por imigrantes LGBTIQ+, na cidade de São Paulo, apontando a uma capacidade própria de articulação desses sujeitos em prol de suas demandas e reivindicações. O evento, que ocorreu em 11 de novembro de 2017 (no galpão da Casa 1), foi organizado por Keyllen Nieto e Lorena Cascallana. Em parceria com o CRAI e com o apoio da Casa 1, o Sarau Troca \& Ação teve entrada gratuita e, como consta no texto de divulgação, aberto "para todos os públicos, incluindo crianças, pois achamos que o momento pede um posicionamento claro da abertura destes espaços para

5 Esse documento pode ser consultado no seguinte link: http://www.acnur.org/fileadmin/scripts/doc.php?file=fileadmin/Documentos/portugues/Publicacoes/2017/Cartilha_Refugiados_LGBTI 
que, no futuro, possamos ter pessoas mais acolhedoras e conscientes na nossa sociedade" (Nieto \& Cascallana, 2017). Ainda de acordo com o referido texto:

\begin{abstract}
0 projeto TROCA \& AÇÃO surge da necessidade de oferecer ações concretas que beneficiem de forma prática a comunidade LGBTIQ, tanto de imigrantes e refugiados de São Paulo como da comunidade LGBTIQ local, através de: atividades de sensibilização e aproximação e projetos artísticos culturais criados em parcerias entre esses dois grupos. Pessoas imigrantes e refugiadas procedem, na maioria das vezes, de lugares e culturas nas quais ser homossexual, bissexual, intersexual ou travesti e pessoa trans é sujeito a forte discriminação, quando não à ameaça da integridade física. Acreditamos que a comunidade LGBTIQ local pode e deve acolher as pessoas imigrantes e refugiadas de diversas orientações sexuais e identidades de gênero existentes na cidade de São Paulo. Queremos incentivar, através da atuação conjunta, a troca de informações, oferecer uma rica experiência de criação colaborativa e fomentar a sensibilização da comunidade local perante as necessidades e desafios enfrentados pelos imigrantes e refugiados.
\end{abstract}

Assim, buscamos explorar, teórica e analiticamente, algumas convergências entre as dinâmicas de (in)visibilidade sociocomunicacionais e seus impactos nas experiências migratórias de sujeitos LGBITQ+, sobretudo no que diz respeito à prática de cidadania.

\title{
Da diáspora queer
}

Se, sob uma ótica culturalista, a diáspora se associa a uma construção da diferença como ontológica (Hall, 2013), por outro lado, relaciona-se aos deslocamentos humanos e às migrações, haja vista que remete à dispersão espacial de determinado grupo, que pode se articular como comunidade (Rouhani, 2016). Com base nesse vínculo, fomenta-se, inclusive, uma dimensão política de sua existência - podemos pensar como exemplos clássicos o povo judeu ou a diáspora africana. Apesar das dinâmicas de dispersão, a origem comum, os vínculos de identificação e a memória coletiva se inter-relacionam, criando acepções da prática de cidadania, por meio de um sentido de pertencimento (Rouhani, 2016). Como anteriormente mencionado, no caso da diáspora queer, esse sentido está perpassado pela abjeção (Wesling, 2008). 
Em termos genéricos, a abjeção remete a um estado de rebaixamento, que pode estar associado à moral, aos costumes e aos sentimentos. Na prática, o sujeito tido como abjeto se torna alvo de ostensivas exclusões, que acabam por levá-lo a um lócus em que o significado de sua existência passa a entrar em colapso (De Genova, 2015). Butler (2011) ressalta que o sujeito abjeto tem a legibilidade da existência deteriorada, o que acarreta perda de significação e importância à sua vida, já que é a "própria humanidade que se torna questionada” (Butler, 2011, p. 161).

A abjeção, assim, configura-se por meio de um encadeamento relacional com uma normalidade hegemonicamente construída, transmutando-se em seu oposto complementar e constitutivo (Butler, 2011). Logo, não pode ser vista como uma característica ou propriedade notadamente externa. Inscrita na materialidade dos corpos, a abjeção emerge como força perturbadora, que desestabiliza, desde o interior, identidades, o sistema normativo e os ditames hegemônicos. Por conta disso, representa um "perigo eminente" (De Genova, 2015).

No caso de migrantes LGBTIQ+, observa-se, na irrupção de uma subjetividade abjeta, certa anomalia tida como nociva tanto à ordem da heterocisnormatividade ${ }^{6}$ quanto à soberania dos atuais Estados-nação, uma vez que sua existência tem o poder de reconfigurar os espaços da política por meio de uma contínua resistência à conjuntura sociocultural que insiste em negá-la. Ou seja, as experiências de vida de sujeitos LGBTIQ+ estão intimamente ligadas ao território e às suas fronteiras (físicas e simbólicas).

Em muitos países, por exemplo, não existem garantias cidadãs ou de direitos a esses sujeitos, que são reconhecidos apenas enquanto objeto de abuso e discriminação. Em decorrência, há a formação de uma comunidade subalterna, constantemente excluída e apagada dos discursos hegemônicos (La Fountain-Stokes, 2004). Em contextos socioculturais altamente repressivos, marcados por abusos provenientes de diversas instituições (Estado, sistema educacional, medicina, Igreja, complexo jurídico etc.), potencializados por dogmas religiosos, costumes, desinformação, condenações morais,

6 Sistema que institui a heterossexualidade e a cisgeneridade como norma hegemônica. 
imaginários estereotipados e preconceitos, o deslocamento se converte em uma possibilidade não apenas de maior liberdade, mas, sobretudo, de sobrevivência - de uma sobrevivência minimamente digna (Mogrovejo, 2015).

Haja vista a fobia a sujeitos LGBTIQ+ que configura de modo estrutural os marcos mais amplos da cultura, a história da diáspora queer é atravessada por clandestinidade e resistência (La Fountain-Stokes, 2004). O simples fato de uma pessoa não ser heterossexual ou não se adequar ao binarismo de gênero (do feminino ou do masculino) se converte em uma poderosa fonte de precariedades e violências, que muitas vezes chegam ao homicídio. ${ }^{7}$ Essas práticas são incentivadas por discursos criminalizantes e patologizantes, ${ }^{8}$ que, ao longo dos séculos, têm se arraigado às vivências de sujeitos LGBTIQ+: perversão, anormalidade, periculosidade, desvio e estigma são características comumente a eles associadas (Mogrovejo, 2015).

O queer se une à diáspora em uma relação de transgressão: ambos são fundamentalmente disruptivos de categorias estáticas do ser, de categorias hegemônicas através das quais subjetividades normativas são produzidas. Logo, gênero e sexualidade são categorias imprescindivelmente necessárias para pensar os efeitos psíquicos, materiais e sociais da globalização, que deve ser entendida em toda sua complexidade (Wesling, 2008).

Fica evidente, nesse sentido, que infringir as normas da heterocisnormatividade pode acarretar uma precarização da existência. É exatamente isso que ocorre com os sujeitos LGBTIQ+, uma vez que passam a ser considerados como uma ameaça à ordem e à "normalidade". Essa precarização inclui insultos, perseguições, violência sexual, prisão arbitrária ou injustificada, tortura e assassinatos (Mogrovejo, 2015). Quanto mais visível for a dissidência, isto é, quanto mais destoar exteriormente do padrão hegemônico, mais riscos o sujeito passa a correr.

7 De acordo com dados do Grupo Gay da Bahia, somente em 2018, foram mais de 400 assassinatos de pessoas LGBTIQ+ em território brasileiro. Esses números podem ser ainda maiores, devido à dificuldade de averiguação da verdadeira causa de morte de pessoas LGBTIQ+ no país (Grupo Gay da Bahia, 2018).

8 Em mais de 70 países, por exemplo, as relações afetivo-sexuais entre pessoas do mesmo gênero são criminalizadas, podendo resultar inclusive em pena de morte (como na Arábia Saudita, no Irã, no Sudão e no Iêmen). Além disso, vale reportar que, somente em 1990, a Organização Mundial da Saúde (OMS) retirou a homossexualidade da Classificação Internacional de Doenças (CID) - até então, era considerada uma patologia. A transexualidade foi entendida como um transtorno de identidade pela CID até o ano de 2018. 
Há, por conseguinte, uma linha de pensamento muito estrita, que também toma a heterossexualidade e a cisgeneridade como normas regulatórias das experiências do sujeito migrante. Isso porque, como previamente assinalado, os sujeitos LGBTIQ+ desafiam em seus deslocamentos transfronteiriços tanto uma metáfora de pertencimento (local, nacional ou internacional) quanto a própria coerência do conceito de "nação". Ser-queer constitui uma resistência móvel entre as barreiras impostas pela normatização do gênero e da sexualidade, bem como pelas fronteiras culturais e nacionais (Wesling, 2008).

No que se refere aos deslocamentos internos (no interior das divisas dos Estados-nação), a migração de áreas rurais a urbanas e de pequenas a grandes cidades ainda é muito recorrente aos sujeitos cujos desejos afetivo-sexuais e/ou identidade de gênero não se conformam à heterocisnormatividade. Os espaços urbanos centrais, com destaque aos grandes conglomerados metropolitanos, exercem uma forte atratividade a sujeitos LGBITQ+, uma vez que representam um lócus singular à construção de suas subjetividades dissidentes. Transmutam-se, portanto, em ambientes onde há a viabilidade de relativo anonimato, menor vigilância social e mais liberdade para a expressão de diferenças (Andrade, 2017). Obviamente, não devemos supor que as violências direcionadas a sujeitos LGBTIQ+ deixem de suceder nesse entorno; todavia, é patente que as características supracitadas podem gerar um sentimento mais profundo de comunidade e pertencimento, que favorece igualmente uma micropolítica de resistência, de cunho protetivo - fomentada, sobretudo, por meio de uma visibilidade sociocomunicacional no âmbito público, cabe salientar.

Já em relação às migrações inter ou transnacionais, devemos considerar duas importantes variáveis. A primeira diz respeito às migrações de caráter voluntário, que podem ser decorrentes de projetos migratórios os mais diversos: estudo, trabalho, vínculos familiares, fatores culturais, socioeconômicos etc. Nesse tipo de mobilidade, a/o migrante não se vê rigorosamente forçada/o a deixar seu país de origem; efetiva um projeto migratório que envolve elementos objetivos e subjetivos, materiais e imaginários. A questão da orientação sexual e/ou identidade de gênero pode 
estar presente, mas de forma indireta, também atuando como um princípio decisivo à migração.

A segunda variável tem a ver com uma categoria específica de deslocamento humano, que engloba o condicionamento a um status migratório regulamentado: o refúgio. Em 1951, na Convenção relativa ao Estatuto dos Refugiados, houve a caracterização da/o refugiada/o como uma pessoa que, "temendo ser perseguida por motivos de raça, religião, nacionalidade, grupo social ou opiniões políticas, encontra-se fora do país de sua nacionalidade e que não pode, ou em virtude desse temor, não quer valer-se da proteção desse país” (ONU, 1951, p. 2). No ano de 1967, com o Protocolo sobre o Estatuto dos Refugiados, esses critérios passaram a valer mais amplamente no quadro do direito internacional no que tange à aceitabilidade dos pedidos de refúgio (Nascimento, 2018). No entanto, em nenhum dos documentos, a orientação sexual ou a identidade de gênero aparecem explicitamente mencionadas como condicionantes válidas à solicitação e à concessão do status de refugiada/o.

Por sua relativa abertura de sentidos, o critério "grupo social" passou ao longo do tempo a abrigar pedidos de refúgio de migrantes que não se enquadravam nos outros quatro, como no caso de mulheres que sofrem violência de gênero em sua sociedade de origem e, posteriormente, sujeitos LGBTIQ+. O primeiro requerimento desse tipo foi deferido na Holanda, na década de 1980 (Nascimento, 2018). Desde então, alguns países ${ }^{9}$ passaram a aceitar que sujeitos LGBTIQ+ fossem abarcados na categoria "grupo social”, dado que os preconceitos, a vulnerabilidade e as violências que enfrentam cotidianamente no país de origem são compreendidos como causas pertinentes à solicitação de refúgio.

Contudo, enquanto não houver uma especificação nas leis que garanta a proteção integral às/aos refugiadas/os LGBTIQ+, a aceitabilidade da solicitação do refúgio e sua outorga ficam dependentes de um entendimento subjetivo do corpo jurídico do Estado-nação de acolhida. Nascimento (2018)

9 Tais como Alemanha, Argentina, Brasil, Bélgica, Canadá, Dinamarca, Espanha, Estados Unidos, Holanda, Reino Unido e Suécia. 
destaca que, nos Estados Unidos, por exemplo, é preciso que se comprove que a/o solicitante de refúgio LGBTIQ+ possui (ou possuía) uma visibilidade social individualizada. Nesse caso, não basta ser LGBTIQ+, tem de parecer LGBTIQ+, ou seja, "externar" características (estereotipadas) de legibilidade que evidenciem uma orientação sexual e/ou identidade de gênero dissidente. Como se pode constatar, esse processo é extremamente complexo e depende de "aprovações" institucionais no país de acolhida, que passam de forma impreterível, além da fundamentação do temor de perseguição, pelo comprovar determinada orientação sexual e/ou identidade de gênero (Nascimento, 2018).

Assim, pode ser redutora a separação analítica das experiências migratórias voluntárias ou forçadas de sujeitos LGBTIQ+. Por vezes, as particularidades de cada um desses projetos migratórios podem se diluir nas experiências comuns de vivenciar os deslocamentos transnacionais, uma vez que a orientação sexual e a identidade de gênero têm um incontestável impacto em sua vida cotidiana e em todas as etapas da mobilidade. Claro que para as/os refugiadas/os LGBTIQ+, a situação é mais crítica, pois a carga de precariedade que recai sobre sua existência é maior, acarretando um nível aprofundado de vulnerabilidade. Porém, o que intentamos ressaltar é o fato de que toda e qualquer experiência de deslocamento de sujeitos LGBTIQ+ está condicionada às normatizações hegemônicas que alicerçam os pilares heterocisnormativos de cada sociedade em que se inserem, o que pode, na prática, apresentar variações de "aceitabilidade" e respeitabilidade da diferença.

Nesse sentido, torna-se evidente que os liames com o exercício de cidadania ficam em algum grau comprometidos aos sujeitos LGBTIQ+ migrantes, tanto no que se refere à concretude dos direitos quanto às relações intersubjetivas que fundamentam a factibilidade de uma prática cidadã, sempre subordinada ao seu caráter relacional. A seguir, passamos a refletir sobre o conceito de "cidadania" para, então, estabelecer uma conexão entre sua funcionalidade e as dinâmicas sociocomunicacionais de (in)visibilidade das quais não pode ser dissociada no caso de sujeitos LGBTIQ+ migrantes. 


\section{A construção da cidadania: da civilidade ao comunicacional}

A cidadania é um conceito que possui sua própria historicidade e que está em constante mutação (Hopenhayn, 2001). Ela pode ser entendida como o resultado de uma prática que envolve diferentes instâncias sociais (formais e informais): uma verdadeira relação política - sempre interdependente - entre um indivíduo e uma comunidade (Cortina, 2005). Para Hopenhayn (2001), ela "se repensa, reescreve e reinscreve em novos espaços sem renunciar aos seus conteúdos históricos” ( $\mathrm{p} .118$, tradução nossa). Isso é aprofundado na contemporaneidade em vista dos impactos de uma globalização cada vez mais ramificada, que remodela o campo político, da cultura e das (r)evoluções nas tecnologias da informação e da comunicação (TICs). Assim, a cidadania é configurada em permanência, passando a ser (re)definida por um descentramento e pela autoafirmação de diferenças entre os sujeitos (Hopenhayn, 2001), que corresponde à sua crescente singularização. Ao ser fragmentada, a cidadania se conforma cada vez mais como exercício.

Quanto à vinculação com os atuais fluxos migratórios, a cidadania se converte em um ponto-chave à sua problematização, colocando em xeque tanto uma ideia de soberania do Estado-nação como a pretensa igualdade de direitos entre os sujeitos naquilo que concerne à sua condição humana. Daí a necessidade de apreender a cidadania como uma prática que compete à tomada de consciência sócio-histórica sobre si mesmo, ou seja, uma real ação proativa, crítica e reivindicativa (ElHajji, 2013). Por sua "condição transacional, as comunidades diaspóricas aprendem a negociar seus direitos e defender suas reivindicações a partir de referenciais jurídicos e filosóficos de matriz humanista que supera as especificidades nacionais e regionais" (ElHajji, 2013, p. 151).

Uma cidadania global ou transnacional supera, assim, a tradicional conformação social, econômica e política para se fundamentar como atitude ética, que ultrapassa o local, cingindo, em sua expansão, o regional, o nacional e o global (ElHajji, 2013). "A ideia de cidadania global não pode, 
por outro lado, ser separada do fenômeno migratório transnacional e da intensificação das trocas simbólicas facilitadas pelas TICs, base material de uma nova esfera pública, naturalmente transnacional” (ElHajji, 2013, p. 151). De fato, as TICs atuam como um recurso imprescindível ao acesso à informação, à (des)construção de imaginários, à criação e ao fomento de redes sociocomunicacionais, e às mobilizações em torno de causas locais e/ou transnacionais.

Além disso, é preciso atentar às intersecções entre essas práticas de cidadania e as (in)visibilidades sociocomunicacionais. Ao tratarmos do que é visível, estamos abordando um conjunto de visualidades que podem (ou não) ser portadoras de uma legibilidade (Rocha, 2009). O vir a ser visível depende, por conseguinte, de lógicas socioculturais partilhadas, capazes de conferir a determinadas imagens uma qualidade de partícipe da ordem coletiva, de onde advém sua relevância social. Como bem sintetiza Rocha (2009), "o que é visível remete, pois, menos ao que se tornou imagem visual e mais àquela visualidade que, via jogo societal e estratégias comunicacionais, é reconhecida como dotada de valor de trocas simbólicas e de relevância comunicativa” (p. 273).

Para imigrantes LGBTIQ+, no entanto, essa política de visibilidade se complexifica. Se, por um lado, precisam se visibilizar para terem ao menos sua existência manifestada no espaço público - lócus primordial aos embates por transformações e cidadania — , por outro, a visibilidade pode se converter em uma fonte de vulnerabilidades. Em uma sociedade e cultura fundamentadas no ordenamento heterocisnormativo dos corpos e das subjetividades, o simples fato de aparentar ser dissidente às suas normatizações representa um real perigo de precarização da existência. A isso se agrega a experiência da clandestinidade, que é intrínseca à migração, já que muitas/os migrantes que não dispõem de regularização jurídica podem temer a visibilidade no espaço público. Nesse sentido, as práticas de cidadania para sujeitos LGBTIQ+ migrantes são entremeadas por um tensionamento entre visibilizar-se ou não; como se visibilizar minimizando riscos de uma precarização ainda mais grave; e quando e em que espaços promover essa visibilidade da diferença. 
Em suma, devemos levar em consideração que a cidadania para migrantes engloba diferentes dimensões: social, jurídica, intercultural e universal. Como exemplo concreto, podemos citar o acesso a serviços públicos, a regularização de documentação, a obtenção de informações, a possibilidade de comunicação com familiares e amigas/os, a inserção no mercado de trabalho e o direito à cultura e ao lazer. Todos esses âmbitos estão transpostos por usos, mediações e apropriações midiáticos, que propiciam uma oferta de representações sobre e das/os migrantes, o estabelecimento e/ou manutenção de redes sociais (locais, nacionais, inter e transnacionais) e demandas por direitos e cidadania, como no caso das políticas de visibilidade (Cogo, 2010). A cidadania se constitui, portanto, como uma questão comunicacional para os mais diversos setores da sociedade civil, haja vista que suas práticas orientam um fluxo constante de produção, recepção e consumo comunicacional. Especificamente na conjuntura diaspórica, as mídias colaboram para articular e manter vínculos, bem como para impulsionar demandas políticas e por cidadania, do que advém o caráter cidadão do comunicacional, preponderante no cotidiano do sujeito migrante. Fica claro como a civilidade, enquanto expressão concreta do contrato social em prol de um convívio coletivo, depende dessas interações que se ensejam em um domínio incontestavelmente comunicacional - $\mathrm{e}$ cada vez mais midiático.

\section{Notas sobre a experiência de campo: entre (in)visibilidades sociocomunicacionais e práticas de cidadania}

O objetivo central da análise das incursões em campo é estabelecer reflexões a respeito de como as (in)visibilidades sociocomunicacionais de imigrantes LGBTIQ+ que habitam na cidade de São Paulo impactam suas vivências, sobretudo no que diz respeito ao exercício de cidadania. Entendemos, portanto, que essas (in)visibilidades se inscrevem amplamente nos modos de experienciar os espaços urbanos (físicos e simbólicos), os serviços sociais e a cultura local, o que se reflete tanto nas demandas por direitos quanto na prática cidadã. 
A pesquisa de campo, portanto, integra-se justamente nos contextos sociais, espaciais e temporais nos quais são articuladas as comunicabilidades que envolvem imigrantes LGBTIQ+ na cidade de São Paulo - compreendendo-as como uma forma de mediação com a realidade e de interação intersubjetiva. Trata-se de um primeiro avanço para estabelecer um aprofundamento empírico com relação à temática. Assim, este estudo permite estipular as perspectivas macrossociais da pesquisa, elaborar algumas considerações referentes às interações de imigrantes LGBTIQ+ na e pela cidade de São Paulo e ponderar sobre as inter-relações entre (in)visibilidade, comunicação e cidadania na perspectiva da diáspora queer.

\section{Passos iniciais}

Como previamente explicitado, as entrevistas realizadas com Ana e Maria objetivaram a verificação da viabilidade da pesquisa, bem como o estabelecimento de um primeiro contato com as experiências de vida de imigrantes LGBTIQ+ na cidade de São Paulo.

Ana é proveniente de uma cidade em Oklahoma, Estados Unidos. No momento da entrevista, ela tinha 45 anos de idade e vivia no Brasil há mais de 15. Após concluir a faculdade, enquanto realizava um intercâmbio no Japão, Ana conheceu Tereza, uma brasileira natural do estado do Espírito Santo. Elas começaram um relacionamento, que continuou mesmo depois do retorno de ambas a seus países de origem. Em 2001, ela decide se mudar para o Brasil para viver com Tereza, sua atual esposa.

A orientação sexual gera uma série de impactos na experiência migratória de Ana. A impossibilidade de regularização da relação com sua companheira, por exemplo, dificulta o processo de integração e é também uma barreira à sua permanência no país. ${ }^{10} \mathrm{~A}$ institucionalização desse tipo de homofobia, propagada nos âmbitos legislativo e jurídico, a faz considerar a

$10 \mathrm{Na}$ época, a união estável entre pessoas do mesmo sexo/gênero ainda não era reconhecida pelo Estado brasileiro. $\mathrm{O}$ reconhecimento de casamento entre pessoas do mesmo sexo no Brasil como entidade familiar, por analogia à união estável, foi declarado possível pelo Supremo Tribunal Federal (STF) em 5 de maio de 2011, no julgamento conjunto da Ação Direta de Inconstitucionalidade (ADI) 4.277 proposta pela Procuradoria-geral da República. Com isso, passou a ser garantido às uniões estáveis homoafetivas todos os direitos conferidos às uniões estáveis entre uma mulher e um homem. No ano de 2013, o Conselho o Nacional de Justiça (CNJ) aprovou uma resolução que obriga os cartórios de todo o país a celebrar o casamento civil e converter a união estável homoafetiva em casamento. 
possibilidade de um casamento heterossexual arranjado, para que assim pudesse acessar um direito que lhe era restrito. Em suas palavras, explica que: "Meu processo de integração se deu em várias etapas. Os primeiros [meses], de julho pra dezembro, eu lutei pra encontrar uma forma de ficar. [...] Eu ia ficar, mas tinha de descobrir como. Eu até cogitei me casar com um amigo nosso" (Ana, 2017). Para além das dificuldades aportadas pelas diferenças culturais e linguísticas, Ana expõe a realidade da vivência de uma homofobia estrutural que deslegitima seus laços afetivos e debilita sua cidadania.

No que se refere propriamente às dinâmicas de (in)visibilidade, é importante salientar que elas marcam várias das experiências de Ana e Tereza, e influenciam diretamente nos múltiplos deslocamentos que elas empreendem (migrando de uma cidade no interior do estado do Espírito Santo para a capital, Vitória, e, mais tarde, para a cidade de São Paulo):

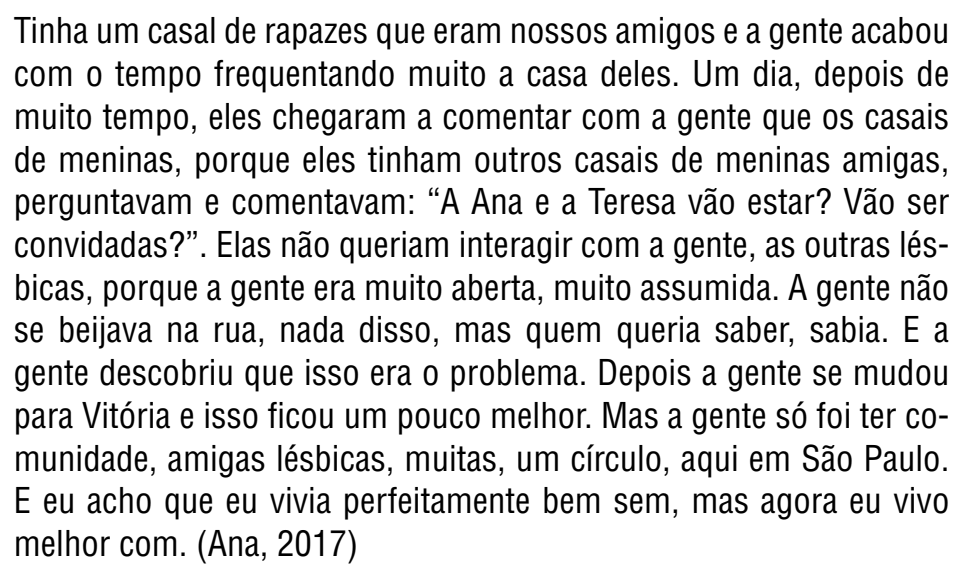

Como podemos verificar em seu relato, Ana e Tereza, quando viviam no interior do estado do Espírito Santo, sofriam discriminação inclusive de outras lésbicas, por conta da visibilidade de sua relação no espaço público - mesmo não envolvendo nenhuma demonstração de afeto. Essa conjuntura somente se altera quando passam a viver na capital, Vitória, e, depois, na cidade de São Paulo, onde conseguem estabelecer uma "comunidade". A experiência de Ana vai ao encontro das reflexões teóricas realizadas anteriormente, ao destacar os profundos vínculos entre a espacialidade e os modos de vivenciar uma orientação sexual e/ou identidade de gêne- 
ro não hegemônica. Além disso, salienta como as dinâmicas de (in)visibilidade são capazes de produzir efeitos concretos em diferentes fases do projeto migratório.

Muito semelhante à problemática do "armário", essa dialética da (in) visibilidade, que representa um dilema à experiência de sujeitos LGBTIQ+ (Theodoro, 2016), fica igualmente manifesta quando Ana conta que a colega com quem dividia apartamento a discriminou ao tomar conhecimento de que ela era lésbica e exigiu que fosse embora:

Quando eu cheguei pra morar, eu fui abrindo isso [sobre a homossexualidade], e ela ficou supermal. Um dia a gente brigou e nessa ela falou pra mim: "Eu não me sinto confortável na minha própria casa. Você deveria ter falado isso pra mim antes de aceitar morar aqui, pra me deixar tomar a decisão." [...] Voltando do feriado, ela chega pra mim na escola e diz: "Eu acho que não vai dar certo, então eu vou ficar na casa da minha mãe até você arranjar um lugar pra morar." [...] Eu não tinha pra onde ir. (Ana, 2017)

A complexidade decorrente das tensões entre visibilizar ou invisibilizar a homossexualidade se transforma em uma fonte de precariedade. Conforme é possível constatar na experiência de Ana, nem sequer o fato de residir em uma metrópole como a cidade de São Paulo representa uma proteção integral nesse sentido.

Maria, por sua vez, tinha 28 anos de idade no momento da entrevista. Ela nasceu em uma pequena cidade da Finlândia, e é filha de mãe finlandesa e pai brasileiro. Maria residiu dos 6 aos 10 anos na cidade de São Paulo, mas retornou à Europa. Em 2012, ela decide imigrar ao Brasil para dar continuidade à sua formação universitária e volta a morar na capital paulista.

No caso de Maria, a principal questão que influencia o projeto migratório e as vivências na cidade de São Paulo é a identidade de gênero. Em seu relato, destaca uma série de dificuldades enfrentadas no país, como, por exemplo, a morosidade na retificação dos documentos, situações de discriminação e violência. Considerando o corpo, em suas visualidades, como mídia - e, por conseguinte, todo seu potencial de comunicação - , torna-se 
evidente como a uma queer-visibilidade também é capaz de gerar vulnerabilidade. Isso demonstra o quão intrincadas são as dinâmicas de (in)visibilidade na diáspora queer.

Na Finlândia, não havia muito essa questão de as pessoas ficarem analisando seus fenótipos. [...] Então, era tranquilo. No Brasil, por sua vez, eu me lembro que meus fenótipos eram muito observados, eram muito questionados. Então, até ter um êxito na transição, eu tive um, digamos... uma certa exclusão social por conta que meus traços não eram nem de um aspecto nem de outro. Outro ponto que eu notei diferença, não que eu tenha passado por isso, mas vi muitas pessoas passando, é a questão da agressão física e verbal. Verbal, sim, eu já passei bastante. Na Finlândia, isso é altamente reprovado. Por mais que a pessoa não concorde e tudo o mais, aquilo fica guardado pra ela. É uma questão cultural de respeito ao outro, ao corpo do outro. (Maria, 2017)

Nessa passagem, fica novamente expresso como a transposição de fronteiras delimitadas pelas normas hegemônicas do gênero conduz o sujeito a um lócus de precariedade que debilita sua inteligibilidade social (Butler, 2011). A experiência de Maria salienta que, no Brasil, essas consequências ainda são muito negativas às pessoas trans, ocasionando situações de violência simbólica e/ou física. Especificamente no que se refere à cidade de São Paulo, o relato de Maria muito se assemelha ao de Ana, ao enfatizar o paradoxo entre uma maior aceitabilidade para com as pessoas LGBTIQ+ e uma espacialidade que continua a replicar uma conjuntura de fobia social contra essa mesma população.

Em relação ao preconceito, São Paulo é uma cidade que tem a pecha
de cosmopolita, mas eu acho ela bem discriminacionista, sim. Você
tem um número muito acentuado de assassinatos por transfobia,
sim. Mas, por outro lado, também é um foco onde tem muitas pes-
soas trans resistindo. Então, a gente tem dois pontos assim muito
curiosos. A gente tem a opressão e a resistência, que cria novas con-
figurações. Então, eu acho que tem um espaço um pouco heterogê-
neo, mas ainda a opressão é muito forte. (Maria, 2017)

A partir das palavras de Maria, compreende-se que a integração ao espaço público não se encontra plenamente assegurada às pessoas LGBTIQ+, o que compromete de maneira direta seu exercício de cidadania. Mesmo 
assim, como podemos observar nas palavras dela, há resistências que tensionam os limites da configuração do espaço público, (re)compondo continuamente os marcos de pertencimento. Voltamos a nos deparar com uma questão basilar: quem, de fato, pode ser cidadã/ão?

O quadro de precariedade verificado nas experiências de Ana e Maria aponta para os múltiplos entraves encontrados por sujeitos LGBTIQ+ migrantes em sua integração ao contexto sociocultural brasileiro. Nesse sentido, podemos observar o quanto as dinâmicas de (in)visibilidade possuem um papel fundamental tanto no projeto migratório quanto nas micropolíticas cotidianas que os sujeitos LGBTIQ+ migrantes estabelecem no contexto sociocultural em que se inserem. Ao mesmo tempo, entremeiam o cerne do exercício de cidadania, pois continuam a exercer uma dupla influência nas experiências de vida de sujeitos LGBTIQ+, sobretudo imigrantes: visibilizar-se ou invisibilizar-se, ser visibilizada/o ou ser invisibilizada/o, são processos que refletem em sua própria existência e na capacidade de agência como atores sociais.

Apesar de suas diferenças, as experiências de vida de Ana e Maria apontam às fraturas da cidadania a migrantes LGBTIQ.$+{ }^{11}$ Se a cidadania corresponde a "se saber e se sentir cidadão de uma comunidade" (Cortina, 2005, p. 27), pode-se facilmente constatar como ela é debilitada em um espaço público que se revela adverso aos sujeitos dissidentes em relação às normas hegemônicas de gênero e/ou de sexualidade (Theodoro e Cogo, 2019). O problema reside justamente no fato de que a legibilidade das visibilidades de sujeitos LGBTIQ+ (incluindo migrantes), que pode ser requerida enquanto uma política de reconhecimento imprescindível à participação no espaço público, é potencialmente precursora de precariedades.

\section{Institucionalidades}

Na ocasião da "Roda de conversa: imigrantes e refugiados/as LGBT em São Paulo: desafios da acolhida e da integração local”, pesquisadoras/es, imigrantes LGBTIQ+, representantes da SMDHC e interessadas/os em geral

11 Cabe reportar que Ana e Maria são mulheres brancas, de classe média e com alto nível de escolarização, o que também são variáveis que influenciam em suas experiências migratórias e nas vulnerabilidades a que estão sujeitas. 
se reuniram no Auditório da Defensoria Pública da União, em São Paulo, para debater acerca das especificidades e vulnerabilidades inscritas na migração de sujeitos LGBTIQ+, da extrema invisibilidade da temática e dos inúmeros obstáculos encontrados tanto no acesso a esses sujeitos quanto na promoção de políticas públicas voltadas às suas necessidades. Foram produzidos encaminhamentos práticos à criação de um plano de trabalho para fomentar os direitos humanos e sociais a migrantes (inclusive refugiadas/os) LGBTIQ+ na capital paulista. ${ }^{12}$ No entanto, desde a mudança de governo na prefeitura de São Paulo, em 2017, quando assumiu João Dória (PSDB), apenas poucas ações pontuais foram logradas nesse sentido, não havendo de fato nenhuma criação e/ou implementação de políticas públicas.

Como exemplo dessas ações pontuais, podemos mencionar o suporte da SMDHC no evento de lançamento da Cartilha informativa sobre a proteção de pessoas refugiadas e solicitantes de refúgio LGBTI, realizado no Centro Cultural São Paulo, em junho de 2017. A cartilha foi desenvolvida pelo ACNUR-ONU e corresponde a um esforço para despertar a atenção - tanto da sociedade de um modo geral quanto das instituições que atuam com esses sujeitos em particular - acerca das especificidades de suas vivências e demandas por direitos e cidadania. De acordo com o ACNUR, o Brasil já registrou mais de 250 solicitações de refúgio de vários países tendo como motivação perseguições a sujeitos LGBTIQ+ e alerta que essa demanda vem aumentando no mundo todo.

É válido reportar que a cartilha, disponível on-line em quatro idiomas (espanhol, francês, inglês e português), converte-se em um material informativo com forte caráter midiático, que implica a visibilidade comunicacional sobre a diáspora queer. É fundamentada nesse potencial comunicacional (e midiático) que visa alertar ao fato de que pessoas refugiadas com uma orientação sexual e/ou identidades de gênero tidas como dissidentes enfrentam riscos, ameaças e vulnerabilidades ao longo de todas as etapas de seu deslocamento, incluindo a inserção no país de acolhida. Obviamente, a cartilha está ligada a uma instituição — ainda que não governamental, o

12 Para mais informações, consultar: http://migramundo.com/poder-publico-e-militancia-debatem-acolhida-de-imigrantes-lgbt-em-sao-paulo/ 
ACNUR é um órgão regulatório - e seu conteúdo fica condicionado ao acesso à internet, o que pode ser um obstáculo; mas, em si, já se configura como um deslocamento do lócus de silenciamento e invisibilidade acerca da diáspora queer.

Assim, ao se voltar à temática de imigrantes (e mais especificamente refugiadas/os) LGBTIQ+, a cartilha exemplifica muito claramente a intersecção entre visibilidade, comunicação e cidadania. ${ }^{13}$ Isso porque, por meio de sua veiculação na mídia (no caso, internet), não apenas visibiliza a existência desses sujeitos, mas também representa um intento em esclarecer tanto a eles quanto à sociedade brasileira quais direitos lhes são assegurados, as dificuldades e as complexidades em lidar com suas experiências migratórias e alguns caminhos que precisam ser percorridos - acima de tudo na direção de uma maior garantia de acesso aos serviços de acolhida, que precisam estar preparados a recebê-los, e da proteção à dignidade humana por parte do Estado.

Já em relação à entrevista com Camila Barrero e Ricardo Olimpio Bezerra na SMDHC, em primeiro lugar, ficou evidente a dificuldade de aproximação a sujeitos LGBTIQ+ imigrantes, uma vez que o "acesso" a uma identidade de gênero e/ou orientação sexual dissidentes passa por um processo de legibilidade. O problema é que nem sempre estão dispostos a assumi-la, haja vista que apenas "parecer" LGBTIQ+ já representa uma matriz de vulnerabilidade e violência (tanto por parte de compatriotas quanto, em maior ou menor grau, pela sociedade de acolhida, a depender dos efeitos da heterocisnormatividade vigente). Nas palavras de Barrero (2017):

Acho que uma das dificuldades que a gente tem na verdade quando a gente pensa nessa população é acessar essa população. Essa é uma das questões que a gente tem no Centro de Referência de Imigrantes: como é que a gente dialoga com culturas diferentes e com símbolos que não sempre fazem sentido nessas culturas diferentes? [...] Como é que a gente faz? A gente coloca uma bandeira LGBT no CRAI para

13 Não levantamos aqui suposições sobre os usos ou apropriações da cartilha, o que depende intrinsecamente do momento de recepção. 
a gente entender que existe um diálogo, uma sensibilidade para falar dessas questões com imigrantes? Mas isso é efetivo? [...] É uma dificuldade muito grande de pensar, porque os símbolos não são os mesmos, a cultura não é a mesma.

Um desafio muito prático [...] era você fazer essa pergunta para as pessoas imigrantes que você estava atendendo, fazendo uma ficha, um formulário, que era: "Orientação sexual". A pessoa me olhava com aquela cara de: "0 que você quer dizer com isso?". Aí você tem de transformar isso em uma pergunta acessível. "Como que você se relaciona sexualmente?". No fim, você tem que fazer a pergunta: "Você é homossexual?". E aí a pessoa fala: “Claro que não". Você não acessa essa informação adequadamente. Então isso é um desafio pro serviço lidar com essa sobreposição de vulnerabilidades.

Andrade (2017) corrobora essas apreensões ao destacar que, no caso de refugiadas/os, por exemplo, quando há outro motivo para a demanda de refúgio que não uma identidade de gênero e/ou orientação sexual não hegemônica, a/o solicitante opta por ela em uma tentativa de autopreservação. O que está em jogo é uma dinâmica de (in)visibilidade: se, por um lado, é preciso que esses sujeitos se tornem visíveis, para que suas demandas sejam ao menos reconhecidas no espaço público (de onde emerge um potencial político de transformação), por outro, como assegurar que a visibilização de uma identidade de gênero e/ou orientação sexual dissidentes não seja de fato um risco à própria vida?

Como podemos notar, outro aspecto importante considerado foram as diferenças culturais das/os imigrantes LGBTIQ+, o que se transforma em dificuldade de comunicação. Isso porque nem todos os símbolos relacionados a sujeitos LGBTIQ+ são universalmente reconhecidos. Camila Barrero aponta, por exemplo, que muitas vezes esses sujeitos não reconhecem a bandeira de arco-íris como um signo de diversidade e receptividade para com diferenças dessa ordem. Fica notório como a construção de uma identidade LGBTIQ+ é relacional, condicional, contextual e, muitas vezes, circunstancial, ou seja, de extrema complexidade.

No que se refere particularmente à institucionalização de políticas públicas, tanto Camila Barrero quanto Ricardo Bezerra destacam que não 
há uma integração forte o suficiente entre o Centro de Cidadania LGBT e os CRAIs. Assim, por mais que esforços sejam empreendidos, comumente imigrantes LGBTIQ+ têm dificuldade de acessar e usufruir os serviços oferecidos pelos Centros de Cidadania LGBT, o que representa um grande desafio a ser superado. Demonstra-se, portanto, uma preocupação ainda incipiente por parte do Estado e de suas instituições em garantir direitos e a viabilidade de uma prática da cidadania às/aos imigrantes LGBTIQ+ residentes na cidade de São Paulo.

\section{O Sarau Troca \& Ação}

O Sarau Troca \& Ação contou com shows musicais, performances, danças, declamação de poesia e exposição de fotografias. Migrantes artistas da Argentina, da Bolívia, da Colômbia, da Itália e do Peru estiveram presentes, destacando uma maior articulação do eixo migratório Sul-Sul.

Das percepções ao participar do Sarau Troca \& Ação, podemos destacar primeiramente o objetivo de uma maior integração entre imigrantes LGBTIQ+ residentes na cidade de São Paulo e a comunidade LGBTIQ+ local. Isso vai ao encontro do que aponta Manalansan IV (2006) ao assinalar que imigrantes LGBTIQ+ geralmente experienciam discriminações e estigmas também por parte do que intitula "cultura mainstream" — isto é, a cultura do país de acolhida —, estendendo a marginalização inclusive dentro da comunidade LGBTIQ+ local.

Manalansan IV (2006) destaca que o quadro de vulnerabilidades pode ser ainda mais agravado por um atravessamento interseccional de marcadores sociais de diferença, como, por exemplo, no caso de imigrantes LGBTIQ+ negras/os. Assim, essa articulação se mostra primordial à quebra de uma primeira camada de invisibilidade e silenciamento. Fazer-se visível e levantar a voz no âmbito dos movimentos LGBTIQ+ locais parece ser um caminho de solidificação de uma (micro)política de (re) existência. Mas, sem dúvida, trata-se de um desafio à própria comunidade LGBTIQ+ local, pois resta saber se ela está pronta a acolher as reinvindicações e demandas de imigrantes LGBTIQ+ nas causas que defende e nas lutas que fomenta. 
De qualquer forma, o que o Sarau Troca \& Ação evidencia (e isso corresponde ao segundo ponto levantado) é a capacidade de agência de imigrantes LGBTIQ+ na cidade de São Paulo e de engajamentos em prol de transformações que dizem respeito à comunidade LGBTIQ+ como um todo. Por meio da arte, de um "artivismo", de uma produção cultural própria, reivindicam espaços e possibilidade de existência, que passa impreterivelmente não apenas pela garantia de direitos, mas também pelo exercício de cidadania, que colabora para a produção de um sentimento de pertença às culturas e às sociedades em que se estabelecem as/os migrantes (Cortina, 2005).

Por fim, é pertinente ressaltar o papel das TICs em todo o processo de realização do Sarau Troca \& Ação, com destaque ao uso do site de rede social Facebook como instrumento de produção, circulação e consumo de conteúdos. Logo, fica claro o quanto esse exercício de cidadania está intimamente arraigado a práticas sociocomunicacionais, especialmente àquelas mediadas por aparatos midiáticos. Além de fomentar novos e eficientes caminhos para se navegar por diferenças culturais, raciais, de classe etc. (Manalansan IV, 2006), as potencialidades de comunicação social das TICs se mostram imprescindíveis aos engajamentos e aos ativismos de imigrantes LGBTIQ+.

\section{Considerações finais: dos desafios da pesquisa}

As reflexões reunidas neste artigo apontam ao mesmo tempo para a multiplicidade $e$ as ambivalências que demarcam as relações entre a mobilidade de sujeitos LGBTIQ+ e as dinâmicas de (in)visibilidade sociocomunicacional nas diferentes etapas de seus processos migratórios e na inserção na cidade de São Paulo. A complexidade que conforma o campo de tensões na diáspora queer opera para que, em termos de disputas de cidadania, tornar-se (in)visível seja uma dimensão sociocomunicacional tanto de produção de precariedades quanto de resistências para imigrantes LGBTIQ+ em contextos institucionais ou não institucionais.

No que se refere às resistências em contextos não institucionais, o trabalho de campo desenvolvido até o momento sugere a produção de es- 
paços que representem micropolíticas de agenciamento por parte de imigrantes e refugiadas/os que, do ponto de vista político, assumam um caráter coletivo e de articulação da comunidade LGBTIQ+ na cidade de São Paulo, como é o caso do Sarau Troca \& Ação, dinamizado por usos de TICs, especialmente sites de redes sociais.

No âmbito institucional, foi possível evidenciar que, a despeito da incipiência das políticas públicas orientadas à realidade da diáspora queer na cidade de São Paulo, a presença de imigrantes e refugiadas/os LGBTIQ+ produz certa desestabilização da ordem heteronormativa, pois reivindica direitos e cidadania, e impulsiona inciativas como a realização do evento "Roda de conversa: imigrantes e refugiados/as LGBTIQ+ em São Paulo: desafios da acolhida e da integração local” e a publicação da Cartilha informativa sobre a proteção de pessoas refugiadas e solicitantes de refúgio LGBTI.

No marco do desenvolvimento da pesquisa, entendemos ser igualmente fundamental refletir sobre essas dinâmicas de (in)visibilidade. Isso é necessário para que não se recaiam sobre os sujeitos migrantes LGBTIQ+ enquadramentos estereotipados nem se celebrem espaços de agenciamento por eles produzidos, uma vez que têm de ser apreendidos em seus limites e possibilidades de engendramento de dinâmicas de resistência e de lutas por cidadania.

\section{Referências}

Alencar-Rodrigues, R., Strey, M. N. e Espinosa, L. C. (2009). Marcos do gênero nas migrações internacionais das mulheres. Psicologia b Sociedade, 21(3), 421-430. https://doi.org/10.1590/S010271822009000300016

Andrade, V. L. (2017). Imigração e sexualidade: solicitantes de refúgio, refugiados e refugiadas por motivos de orientação sexual na cidade de São Paulo (dissertação de mestrado). Programa de Pós-graduação em Antropologia Social da Universidade Federal de Santa Catarina, Florianópolis. 
Assis, G. O. (2007). Mulheres migrantes no passado e no presente: gênero, redes sociais e migração internacional. Estudos feministas, 15(3), 745-772. https://doi.org/10.1590/S0104-026X2007000300015

Butler, J. (2011). Vida precária. Contemporânea, 1, 13-33. http://www.contemporanea.ufscar.br/index.php/contemporanea/article/view/18

Cogo, D. (2010). A Comunicação cidadã sob o enfoque do transnacional. Intercom - Revista Brasileira de Ciências da Comunicação, 33(1), 81-103. http://www.portcom.intercom.org.br/revistas/index. $\mathrm{php} /$ revistaintercom/article/view/148

Cortina, A. (2005). Cidadãos do mundo: para uma teoria da cidadania. São Paulo: Loyola.

De Genova, N. (2015). As políticas queer de migração: reflexões sobre "ilegalidade" e incorrigibilidade. REMHU - Revista Interdisciplinar de Mobilidade Humana, XXIII(45), 43-75. DOI: https: //doi. org/10.1590/1980-8585250319880004503

ElHajji, M. (2013). Comunidades diaspóricas e cidadania global: o papel do intercultural. Esferas, 2(3), 145-151. https://portalrevistas.ucb. br/index.php/esf/article/view/4632/

Hall, S. (2013). Pensando a diáspora. Reflexões sobre a terra no exterior. Em S. Hall (org.), Da diáspora: identidades e mediações culturais (pp. 27-55). Belo Horizonte: Editora UFMG.

Grupo Gay da Bahia. (2018). População LGBT morta no Brasil. \#Relatório 2018. https://grupogaydabahia.files.wordpress.com/2020/03/ relatorio-2018.pdf

Hopenhayn, M. (2001). Viejas y nuevas formas de la ciudadanía. Revista de la CEPAL, 73, 117-128. https://www.cepal.org/es/publicaciones/10722-viejas-nuevas-formas-la-ciudadania 
Krzeslo, E. (2007). Migrations et parcours d'exil: les femmes s'imposent. REMHU - Revista Interdisciplinar da Mobilidade Humana, $X V(29), 121-137 . h t t p: / /$ remhu.csem.org.br/index.php/remhu/ article/view/61

La Fountain-Stokes, L. (2004). De sexilio(s) y diáspora(s) homosexual(es) latina(s): cultura puertorriqueña y lo nuyorican queer. Debate $f e-$ minista, 29, 138-157. http://www.debatefeminista.cieg.unam.mx/ wp-content/uploads/2016/03/articulos/029_09.pdf

Manalansan IV, M. (2006). Queer intersections: sexuality and gender in migration studies. The International Migration Review, 40(1), 224249. https://doi.org/10.1111/j.1747-7379.2006.00009.x

Mogrovejo, N. (2015). Disidencia sexual y ciudadanía en la era del consumo neoliberal. Ciudad de México: Universidad Autónoma de la Ciudad de México.

Nascimento, D. B. (2018). Refúgio LGBTI: panorama nacional e internacional. Porto Alegre: Editora Fi.

Nieto, K. \& Cascallana, L. $1^{\circ}$ Sarau TROCA \& AÇÃO: imigrantes, refugiados e artistas LGBTI. (2017, novembro 11). O projeto TROCA \& $A C ̧ \tilde{A} O$ surge da necessidade de oferecer ações concretas que beneficiem de forma prática a comunidade LGBTIQ [detalhes evento no Facebook]. https://www.facebook.com/events/338256483313807

Organização das Nações Unidas [ONU]. ([1951] 14 de outubro de 2018). Convenção Relativa ao Estatuto dos Refugiados. http:/ /www.acnur. org/fileadmin/Documentos/portugues/BDL/Convencao_relativa_ao_Estatuto_dos_Refugiados.pdf

Rocha, R. M. (2009).É a partir de imagens que falamos de consumo: reflexões sobre fluxos visuais e comunicação midiática. Em G. S. Castro e M. A. Baccega (eds.), Comunicação e consumo nas culturas locais e global (pp. 268-293). São Paulo: ESPM. 
Rouhani, F. (2016). Queer political geographies of migration and diaspora. Em G. Brown e K. Browne (orgs.), The Routledge Research Companion to Geographies of Sex and Sexualities (pp. 229-236). Nova York: Routledge.

Theodoro, H. (2016). Transgeneridade, mídia e consumo: um estudo de caso das visibilidades midiáticas de Laerte Coutinho (dissertação de mestrado). Escola Superior de Propaganda e Marketing, São Paulo.

Theodoro, H. e Cogo, D. (2019). Fluxos migratórios, comunicação e cidadania: vivências de imigrantes LGBT na cidade de São Paulo. Intexto, 44, 57-73. http://dx.doi.org/10.19132/1807-8583201944.57-73

Wesling, M. (2008). Why queer diaspora? Feminist Review, 90(1), 30-47. DOI: https://doi.org/10.1057/fr.2008.35 